Carla Thais Rosada PERUCHI(a) Regina Célia POLI-FREDERICO(b) Alexandrina Aparecida Maciel CARDELLI(c)

Marina de Lourdes Calvo FRACASSO (a)

Carina Gisele Costa BISPO(a)

Rejane Dias NEVES-SOUZA ${ }^{(\mathrm{d})}$

Jefferson Rosa CARDOSO(e)

Sandra Mara MACIEL(a)

(a) Universidade Estadual de Maringá - UEM, School of Dentistry, Maringá, PR, Brazil.

(b) Universidade do Norte do Paraná - UNOPAR, School of Dentistry, Londrina, PR, Brazil.

(c) Universidade Estadual de Londrina - UEL, Nursing School, Londrina, PR, Brazil.

(d) Universidade do Norte do

Paraná - UNOPAR, Nutrition School, Londrina, PR, Brazil.

(e) Universidade Estadual de Londrina - UEL, Laboratory of Biomechanics and Clinical Epidemiology, PAIFIT Research Group, Londrina, PR, Brazil.

Declaration of Interests: The authors certify that they have no commercial or associative interest that represents a conflict of interest in connection with the manuscript.

Corresponding Author:

Sandra Mara Maciel

E-mail: sandramaciel53@gmail.com

DOI: 10.1590/1807-3107BOR-2016.vol30.0116

Submitted: July 6, 2015

Accepted for publication: July 11, 2016

Last revision: Aug 24, 2016

\section{Association between oral health status and central obesity among Brazilian independent-living elderly}

\begin{abstract}
The aim of this study was to investigate the association between oral health status and central obesity (CO) in Brazilian independent-living elderly. A cross-sectional study was carried out in a sample of 489 elderly, who were participants of the Study on Aging and Longevity, in Londrina, state of Parana. The number of natural teeth and use of prostheses were evaluated according to the World Health Organization criteria. The presence of $\mathrm{CO}$ was assessed using measures of waist circumference (WC) and waist-hip ratio (WHR). Information concerning sociodemographic profile and some systemic conditions was also collected. Data were analyzed using stepwise logistic regression, $\mathrm{a}=5 \%$. According to WC and WHR measures, the prevalence of central obesity was $79.3 \%$ and $76.1 \%$, respectively. $\mathrm{CO}$ according to WC was not associated with oral status. Considering the WHR measure, the following oral conditions were associated to CO: having fewer natural teeth $(\mathrm{OR}=2.61 ; 95 \% \mathrm{CI}=1.17-5.80)$, being edentulous and wearing both upper and lower complete dentures $(\mathrm{OR}=2.34 ; 95 \% \mathrm{CI}=1.11-4.93)$, and being edentulous wearing only the upper complete denture $(\mathrm{OR}=2.64 ; 95 \% \mathrm{CI}=1.01-6.95)$. Traditional risk factors for $\mathrm{CO}$ such as gender, dyslipidemia, hypertension and diabetes were associated with both measures. A poor oral health due to extensive tooth loss, whether partial or complete, even if rehabilitated by removable prostheses, may be considered a good predictor of $\mathrm{CO}$ in Brazilian independent-living elderly.
\end{abstract}

Keywords: Oral Health; Tooth Loss; Obesity, Abdominal; Aged.

\section{Introduction}

The aging of the population represents a reality throughout the world ${ }^{1}$. It is estimated that Brazil will be the sixth country in total population of older people by $2025^{2}$, reaching 64 million inhabitants in 2050, about $30 \%$ of its total population ${ }^{3}$. The economic impact of this process in health systems has been a reason for concern for health and social policy-makers. The challenge, in addition to providing adequate health assistance, is to implement public policies that will promote general health, by controlling risk factors that are common to noncommunicable diseases (NCDs), highly prevalent among the elderly population ${ }^{4}$.

Obesity has a multi-factorial nature, and it can be modulated by an individual's eating habits ${ }^{5}$. It is associated to cardiovascular diseases, such 
as arterial hypertension, dyslipidemia, and type- 2 diabetes, thus contributing to an increased burden of NTCDs ${ }^{6}$. The World Health Organization (WHO) regards the metabolic syndrome (of which the main characteristic is the presence of abdominal obesity) as the greatest and most prevalent risk factor for cardiovascular diseases (CVDs). Mortality due to CVDs increases with age, and is the main cause of death in Brazil, as well as in other countries around the world, accounting for $30 \%$ of global deaths ${ }^{8}$.

The association between oral health status and factors that increase the risk of developing cardiovascular diseases has been the aim of several

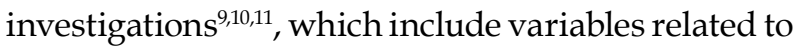
eating patterns and nutritional status in their analyzes. It is known that the oral health status may interfere in people's food choices ${ }^{12,13,14}$. As an example, tooth loss may lead to chewing and swallowing problems, and therefore affect the early digestive process, nutrient intake, and appetite itself, leading to the adoption of a softer, more processed diet ${ }^{12,13}$. This diet is usually poor in nourishing terms, affecting the individual's general health, leading to increased levels of cholesterol, triglycerides, and obesity, and raising the risks of developing cardiovascular diseases ${ }^{11,15,16,17,18}$.

The literature that addresses the relationship between the oral health status of independent elderly and the presence of obesity is conflicting. Some studies found an association between edentulous persons and low weight ${ }^{12,18,19,20}$. Others, however, report that dentate elderly with few teeth and those that were edentulous, even if rehabilitated with complete dentures, were more likely to be obese. ${ }^{13,15,16,17}$ Few researchers took into consideration central tendency measurements to assess the presence of obesity ${ }^{16,17}$, which are regarded as more appropriate to evaluate the risk of developing cardiovascular diseases ${ }^{22}$. The results of two large-scale international studies involving various countries showed that the measure of waist circumference (WC) ${ }^{22}$ and waist-hip ratio $(\mathrm{WHR})^{23}$ were stronger predictors of cardiovascular diseases than the Body Mass Index (BMI).

Tooth loss and edentulism in Brazil affect about $94 \%$ of the individuals between 65 and 74 years of age $^{24}$. These conditions have a negative impact on quality of life of the elderly from a social standpoint, owing to a low self-esteem and self-image ${ }^{25}$. Also, they impair the quality of their dietary intake $\mathrm{k}^{13,14,26,27}$, and may increase the risk of developing various health-related problems.

The aim of this study was to investigate the relationship between the oral health status and the presence of central obesity $(\mathrm{CO})$ in Brazilian independent-living elderly.

\section{Methodology}

\section{Study design}

This cross-sectional, observational study is part of a larger thematic project: the EELO Project - Brazilian acronym for "Study on Aging and Longevity", which was carried out between February 2010 and November 2013 by an interdisciplinary team of the North University of Paraná (UNOPAR), in a partnership with the Departments of Health and of the Elderly in Londrina, a city in Southern Brazil. The EELO aimed to outline a regional epidemiological profile covering social-demographic and health related indicators for the elderly. Information about the project can be found at http://www2.unopar.br/sites/eelo/. The research was authorized by the Municipal Health Authorities of Londrina, and certified by the National Health Council. All participants provided written informed consents.

\section{Population and sample}

The sample of the EELO Project was obtained from a total of 43,610 elders registered in 38 Basic Health Units in the urban area of the city ${ }^{28}$.

A minimum sample size of 396 was defined based on the formula proposed by Barbetta ${ }^{29}$, considering a $95 \%$ confidence interval and a 5\% sampling error. To extend the opportunity of performing health assessments to a greater number of individuals, the project coordinators increased the sample to 520 elderly.

A stratified random sampling method was used considering the municipality's five regions (15\% were from the central, $27 \%$ from the northern, $23 \%$ from the southern, $19 \%$ from the eastern, and $16 \%$ from the western regions). Participants were randomly selected based on individual registries in the Family Health Program. 
For the field work, small groups of participants were transported from their respective health units to the UNOPAR Research Center. Each evaluation was performed in three days of the same week, and complete data collection, which included structured interviews and a set of 48 different evaluations, was achieved within 18 months. As not all participants attended every session, the final sample consisted of 489 individuals who participated in both the oral and nutritional assessments.

The study included elderly $\geq 60$ years old, of both genders, living independently and classified at level 3 or 4 , as proposed by Spirduso ${ }^{30}$, which means that they were able to perform basic activities of daily life.

\section{Data collection}

The sociodemographic information was obtained through interviews using a structured questionnaire that comprised the following variables: gender (male/female), age (60 to 64 years/ 65 to 74 years/ $\geq 75$ years), living condition (lives with someone/ alone), schooling ( $\leq 4$ years of education/ >4 years) and economic class (A1, A2, B1, B2, $\mathrm{C} 1, \mathrm{C} 2$, D and E), which were based on the Brazil Economic Classification criterion ${ }^{31}$. For statistical purposes, classes were grouped into the following categories: "upper" (A and B), "middle" (C) and "lower" (D and E).

Oral health assessment included the number of natural teeth and the use of prostheses for both arches, according to $\mathrm{WHO}$ criteria $^{32}$. The number of natural teeth consisted of a discrete variable from 0 to 32 . Individuals who did not have a single natural tooth in both arches were regarded as totally edentulous. Clinical examinations were performed at UNOPAR Dental Clinic by a single examiner. Based on their oral health status, the elderly were grouped into five categories as follows: edentulous wearing upper and lower complete dentures (2CD); edentulous wearing only the upper complete denture (1 CD), dentate with 1 to 9 teeth, dentate with 10 to 19 teeth, and dentate with 20 or more teeth. The grouping by number of teeth and use of dentures has been reported in previous studies ${ }^{19,20}$.

For the investigation of the lipid profile of the elderly (triglycerides, total cholesterol, HDL-c and LDL-c) and the presence of diabetes (blood levels of glycated hemoglobin - HbA1C > 6.5\%), blood samples were collected by trained students of the UNOPAR Undergraduate Course of Pharmacy and sent to Cetel Laboratory in Londrina, for biochemical analysis. Based on the results, the elderly were classified into: presence or absence of dyslipidemia (according to the parameters described in the V Brazilian Guidelines on Dyslipidemia and Prevention of Atherosclerosis ${ }^{21}$ ), and diabetic or non-diabetic.

Arterial blood pressure was obtained with a semi-automatic apparatus (OMRON - HEM 705 $\mathrm{CP}$ ), following specific procedures ${ }^{33}$. Individuals with systolic blood pressure $\geq 140 \mathrm{mmHg}$ and diastolic blood pressure $\geq 90 \mathrm{mmHg}$ or on current use of antihypertensive medication were regarded as hypertensive. Smoking was assessed by self-reported information, and individuals were classified into smoker, former smoker, and non-smoker ${ }^{34}$.

The dependent variables, for central obesity classification, were obtained by the anthropometric perimeter measures waist circumference (WC) and waist-hip ratio (WHR). Three consecutive measurements were taken by postgraduate students of the UNOPAR Course of Nutrition, and averaged.

WC and WHR were assessed according to internationally pre-established parameter ${ }^{25}$. Men with a WC $\geq 94 \mathrm{~cm}$ and women with a $W C \geq 80 \mathrm{~cm}$ were regarded as having central obesity ${ }^{35}$. WHR was determined by the following equation: $[\mathrm{WHR}=\mathrm{WC} /$ hip circumference $(\mathrm{cm})]$, which reflects the distribution of central fat. Men with a ratio $>1$ and women $>0.85$ were considered as having central obesity ${ }^{36}$.

\section{Statistical analysis}

Relative and absolute frequencies were obtained by descriptive analysis. A univariate analysis and crude odds ratio $(95 \% \mathrm{CI})$ were employed to assess associations between central obesity (through WC and WHR) and the independent variables. Statistically significant values from the univariate analysis were used in the stepwise logistic regression model (forward likelihood ratio), and adjusted odds ratios $(95 \% \mathrm{CI})$ were obtained.

To analyze the independent variables, two tests were applied: the omnibus chi-square test of model coefficients, to verify if the set of variables improves 
the prediction of the log odds and the Nagelkerke $\mathrm{R}^{2}$ to investigate which variables could explain a low sum of variance. Hosmer and Lemeshow goodness-of-fit was used to assess if the observed values were close to expected. The accuracy of the prediction model was tested to check the ability to accurately classify people into one of the two categories of $\mathrm{CO}$, for both anthropometric measures. For the stepwise regression analysis, the probability for variable entry or removal of the model were set to $0.05^{37}$. Statistical significance was set at $5 \%$ and all analyses were performed with SPSS version 20 (IBM SPSS®, Armonk, NY, USA).

\section{Results}

Among the 489 elders who participated in this study, there was a predominance of females (66.5\%), of the age group 65 to 74 years (54.2\%), of low level of schooling (80.4\%), and of middle social class (63.8\%). Based on their oral conditions, $10.8 \%$ were edentulous with 1 complete denture, $36.8 \%$ were edentulous with 2 complete dentures, $24.5 \%$ were dentate with 1 to 9 teeth, $15.1 \%$ had 10 to 20 teeth and $12.7 \%$ had 20 or more teeth. The prevalence of $\mathrm{CO}$ was $79.3 \%$ and $76.1 \%$, based on WC and WHR, respectively.

Four steps were necessary in the first model (WC) with accuracy of $79.2 \%$. In the second model (WHR), five steps were found with accuracy of $80.9 \%$. The independent variables that were significantly associated with the presence of $\mathrm{CO}$, according to WC and WHR, are shown in Tables 1 and 2, respectively.

Considering WC as the indicator (Table 1), after adjustment by stepwise logistic regression, the following variables remained associated to increased odds of having $\mathrm{CO}$ : female gender $(\mathrm{OR}=5.20$; 95\%CI: 3.13-8.64), presence of dyslipidemia ( $\mathrm{OR}=2.01$; 95\%CI: 1.19-3.37), presence of hypertension ( $\mathrm{OR}=2.49$; 95\%CI: 1.48-4.17), and presence of diabetes ( $\mathrm{OR}=4.09$; 95\%CI: 1.97-8.48). Está muito espremido e faltaram os espaços. Having 10 to 19 natural teeth $(\mathrm{OR}=2.03$; 95\%CI: 0.81-5.16), 1 to 9 natural teeth (OR $=2.33$; 95\%CI: 0.98-5.55) and being edentulous wering two complete dentures (OR $=1.46$; 95\%CI: 0.65-3.30) did not remain associated to $\mathrm{CO}$ after the adjusted analysis.

According to WHR (Table 2), the following variables remained associated to increased odds of $\mathrm{CO}$ : female gender $(\mathrm{OR}=6.71 ; 95 \% \mathrm{CI}$ : $4.04-11.18)$, presence of dyslipidemia (OR $=2.12 ; 95 \% \mathrm{CI}$ : 1.27-3.51); presence of hypertension (OR = 1.90; 95\%CI: 1.15-3.13); and presence of diabetes (OR $=4.37$; 95\%CI: 2.22-8.61). Also, the following oral characteristics retained the association after model adjustment: edentulous wearing only upper complete dentures $(\mathrm{OR}=2.64$; 95\%CI: 1.01-6.95); edentulous wearing upper and lower complete dentures (OR $=2.34 ; 95 \% \mathrm{CI}$ : 1.11-4.93); and dentate with 1 to 9 natural teeth $(\mathrm{OR}=2.61$; 95\%CI: 1.17-5.80).

\section{Discussion}

Hypertension, diabetes, and the presence of dyslipidemia are factors commonly associated with obesity, and are risk factors for the development of cardiovascular diseases ${ }^{21}$. The present investigation showed that partial and complete tooth loss are associated to $\mathrm{CO}$ even after adjusting for these traditional risk markers. Statistical associations were found between poor oral health status and CO only when WHR was used as the anthropometric measure of fat distribution.

The maintenance of a functional natural dentition, defined as having more than 20 natural teeth, plays an important role in maintaining a satisfactory nutritional status ${ }^{13}$. Compared to having a functional dentition, having few natural teeth increased the odds of central obesity by 2.61 times, taking the WHR as reference. Still according to WHR, the odds of CO increased with the presence of edentulism and upper and lower dentures (2.34 times), and with edentulism and only upper denture (2.64 times).

Our results showing that edentulous individuals rehabilitated by total removable prostheses have an unsatisfactory nutritional status considering the diagnosis of abdominal obesity corroborate the findings of other authors ${ }^{12,15,16,18}$. Despite distinct methodologies, those studies showed associations between edentulism and the presence of obesity. Hilbert et al. ${ }^{15}$ and Tôrres et al. ${ }^{18}$, who used BMI measures for obesity definition, reported that totally edentulous individuals wearing only the upper denture had greater chances of suffering from obesity. Likewise in the present investigation, edentulous individuals rehabilitated only with a complete upper denture had greater chances of having central obesity than those totally rehabilitated, with WHR as a 
Table 1. Stepwise logistic regression between the independent variables and the presence of central obesity (CO), as established by the measure of waist circumference (WC) in the elderly $(n=489)$.

\begin{tabular}{|c|c|c|c|c|c|c|}
\hline \multirow{2}{*}{ Variable } & Without CO & With CO & Crude OR & \multirow{2}{*}{$p$} & Adjusted OR & \multirow{2}{*}{$\mathrm{p}$} \\
\hline & n (\%) & n (\%) & $95 \%(\mathrm{Cl})$ & & $95 \%(\mathrm{Cl})$ & \\
\hline \multicolumn{7}{|l|}{ Gender } \\
\hline Male & $67(66.3)$ & 97 (25.0) & 1.0 (ref.) & - & 1.0 (ref.) & - \\
\hline Female & 34 (33.7) & $291(75.0)$ & $5.91(3.68-9.48)$ & $<0.001$ & $5.20(3.13-8.64)$ & $<0.001$ \\
\hline \multicolumn{7}{|l|}{ Age in years } \\
\hline 60 to 64 & $19(18.8)$ & $105(27.1)$ & 1.0 (ref.) & - & 1.0 (ref.) & - \\
\hline 65 to 74 & $55(54.5)$ & $210(54.1)$ & $0.69(0.39-1.22)$ & 0.205 & $0.68(0.34-1.37)$ & 0.280 \\
\hline 74 and + & $27(26.7)$ & 73 (18.8) & $0.48(0.25-0.94)$ & 0.033 & $0,48(0.21-1.11)$ & 0.087 \\
\hline \multicolumn{7}{|l|}{ Living condition } \\
\hline With someone & $77(76.2)$ & $241(62.1)$ & 1.0 (ref.) & - & 1.0 (ref.) & - \\
\hline Alone & $24(23.8)$ & $147(37.9)$ & 1.95 (1.18-3.23) & 0.009 & $1.42(0.78-2.59)$ & 0.254 \\
\hline \multicolumn{7}{|l|}{ Schooling in years } \\
\hline$>4$ & $13(12.9)$ & $83(21.4)$ & 1.0 (ref.) & - & - & - \\
\hline$\leq 4$ & $88(87.1)$ & $305(78.6)$ & $6.38(0.28-1.02)$ & 0.058 & - & - \\
\hline \multicolumn{7}{|l|}{ Economic class } \\
\hline Upper & $17(16.8)$ & $66(17.0)$ & 1.0 (ref.) & - & - & - \\
\hline Middle & $62(61.4)$ & $250(64.4)$ & $1.03(0.56-1.89)$ & 0.902 & - & - \\
\hline Lower & $22(21.8)$ & $72(18.6)$ & $0.84(0.41-1.72)$ & 0.640 & - & - \\
\hline \multicolumn{7}{|l|}{ Dyslipidemia } \\
\hline No & $53(52.5)$ & $103(26.5)$ & 1.0 (ref.) & - & 1.0 (ref.) & - \\
\hline Yes & $48(47.5)$ & $285(73.5)$ & 3.05 (1.94-4.79) & $<0.001$ & $2.01(1.19-3.37)$ & 0.009 \\
\hline \multicolumn{7}{|l|}{ Smoking } \\
\hline Never & $53(51.5)$ & $244(62.9)$ & 1.0 (ref.) & - & 1.0 (ref.) & - \\
\hline Former smoker & $36(35.6)$ & $119(30.7)$ & $0.69(0.43-1.12)$ & 0.142 & $1.37(0.47-2.51)$ & 0.314 \\
\hline Current smoker & $13(12.9)$ & $25(6.4)$ & $0.40(0.19-0.84)$ & 0.016 & $0.58(0.25-1.37)$ & 0.219 \\
\hline \multicolumn{7}{|l|}{ Hypertension } \\
\hline No & $58(57.4)$ & $117(30.2)$ & 1.0 (ref.) & - & 1.0 (ref.) & - \\
\hline Yes & $43(42.6)$ & $271(69.8)$ & $3.16(2.01-4.97)$ & $<0.001$ & $2.49(1.48-4.17)$ & 0.001 \\
\hline \multicolumn{7}{|l|}{ Diabetes } \\
\hline No & $90(89.1)$ & $248(63.9)$ & 1.0 (ref.) & - & 1.0 (ref.) & - \\
\hline Yes & 11 (10.9) & $140(36.1)$ & $4.63(2.39-4.97)$ & $<0.001$ & 4.09 (1.97-8.48) & $<0.001$ \\
\hline \multicolumn{7}{|l|}{ Oral status } \\
\hline 20 or + teeth & $20(19.8)$ & $42(10.8)$ & 1.0 (ref.) & - & 1.0 (ref.) & - \\
\hline 10 to 19 teeth & $13(12.9)$ & $61(15.7)$ & $2.34(1.05-5.19)$ & 0.036 & $2.03(0.81-5.16)$ & 0.132 \\
\hline 1 to 9 teeth & $18(17.8)$ & $102(26.3)$ & $2.86(1.38-5.90)$ & 0.004 & $2.33(0.98-5.55)$ & 0.056 \\
\hline Edentulous with $2 \mathrm{CD}$ & $35(34.7)$ & $145(37.4)$ & $2.04(1.07-3.87)$ & 0.029 & $1.46(0.65-3.30)$ & 0.354 \\
\hline Edentulous with $1 \mathrm{CD}$ & 15 (14.9) & $38(9.8)$ & $1.39(0.62-3.11)$ & 0.429 & $1.38(0.51-3.75)$ & 0.530 \\
\hline
\end{tabular}

$\mathrm{CD}$ : complete removable denture; Constant model: estimate $=-0.81 ; \mathrm{SE}=0.26 ; \chi^{2}$ wald $=9.78 ; \mathrm{p}=0.002$. 
Association between oral health status and central obesity among Brazilian independent-living elderly

Table 2. Stepwise logistic regression between the independent variables and the presence of central obesity (CO), as established by waist-hip ratio(WHR) in the elderly $(n=489)$.

\begin{tabular}{|c|c|c|c|c|c|c|}
\hline \multirow{2}{*}{ Variable } & Without CO & With CO & Crude OR & \multirow{2}{*}{$\mathrm{p}$} & Adjusted OR & \multirow{2}{*}{$\mathrm{p}$} \\
\hline & n (\%) & n (\%) & $95 \%(\mathrm{Cl})$ & & $95 \%(\mathrm{Cl})$ & \\
\hline \multicolumn{7}{|l|}{ Gender } \\
\hline Male & $81(69.2)$ & $83(22.3)$ & 1.0 (ref.) & & 1.0 (ref.) & \\
\hline Female & $36(30.8)$ & $289(77.7)$ & $7.83(4.93-12.42)$ & $<0.001$ & $6.71(4.04-11.18)$ & $<0.001$ \\
\hline \multicolumn{7}{|l|}{ Age in years } \\
\hline 60 to 64 & $23(19.7)$ & $101(27.1)$ & 1.0 (ref.) & & & \\
\hline 65 to 74 & $68(58.1)$ & $197(53.0)$ & $0.66(0.38-1.12)$ & 0.124 & - & \\
\hline 74 and + & $26(22.2)$ & 74 (19.9) & $0.64(0.34-1.22)$ & 0.182 & - & \\
\hline \multicolumn{7}{|l|}{ Living condition } \\
\hline With someone & $88(75.2)$ & $230(61.8)$ & 1.0 (ref.) & & 1.0 (ref.) & \\
\hline Alone & $29(24.8)$ & 142 (38.2) & 1.87 (1.17-2.99) & 0.009 & $1.01(0.62-1.92)$ & 0.754 \\
\hline \multicolumn{7}{|l|}{ Schooling in years } \\
\hline$>4$ & $20(17.1)$ & $76(20.4)$ & 1.0 (ref.) & & & \\
\hline$\leq 4$ & $97(82.9)$ & $296(79.6)$ & $1,24(0.72-2.14)$ & 0.429 & - & \\
\hline \multicolumn{7}{|l|}{ Economic class } \\
\hline Upper & $25(21.4)$ & $58(15.6)$ & 1.0 (ref.) & & & \\
\hline Middle & $70(59.8)$ & $242(65.1)$ & 1.49 (0.86-2.55) & 0.147 & - & \\
\hline Lower & $22(18.8)$ & $72(19.4)$ & $1.41(0.72-2.75)$ & 0.314 & - & \\
\hline \multicolumn{7}{|l|}{ Dyslipidemia } \\
\hline No & $60(51.3)$ & $96(25.8)$ & 1.0 (ref.) & & 1.0 (ref.) & \\
\hline Yes & $57(48.7)$ & $276(74.2)$ & $3.02(1.96-4.65)$ & $<0.001$ & $2.12(1.27-3.51)$ & 0.004 \\
\hline \multicolumn{7}{|l|}{ Smoking } \\
\hline Never & $59(50.4)$ & $237(63.7)$ & 1.0 (ref.) & & 1.0 (ref.) & \\
\hline Former smoker & $44(37.6)$ & $111(29.8)$ & $0.63(0.40-0.98)$ & 0.043 & $1.09(0.61-1.97)$ & 0.762 \\
\hline Current smoker & $14(12.0)$ & $24(6.5)$ & $0.43(0.21-0.85)$ & 0.020 & $0.64(0.27-1.52)$ & 0.318 \\
\hline \multicolumn{7}{|l|}{ Hypertension } \\
\hline No & $61(52.1)$ & $114(30.6)$ & 1.0 (ref.) & & 1.0 (ref.) & \\
\hline Yes & $56(47.9)$ & $258(69.4)$ & $2.46(1.61-3.77)$ & $<0.001$ & $1.90(1.15-3.13)$ & 0.012 \\
\hline \multicolumn{7}{|l|}{ Diabetes } \\
\hline No & $103(88.0)$ & $235(63.2)$ & 1.0 (ref.) & $<0.001$ & 1.0 (ref.) & $<0.001$ \\
\hline Yes & $14(12.0)$ & $137(36.8)$ & $4.29(2.36-7.78)$ & & $4.37(2.22-8.61)$ & \\
\hline \multicolumn{7}{|l|}{ Oral status } \\
\hline 20 or + teeth & $26(22.2)$ & $36(9.7)$ & 1.0 (ref.) & & 1.0 (ref.) & \\
\hline 10 to 20 teeth & $23(19.7)$ & $51(13.7)$ & $1.66(0.82-3.35)$ & 0.155 & $1.18(0.52-2.68)$ & 0.691 \\
\hline 1 to 9 teeth & $22(18.8)$ & $98(26.3)$ & $3.37(1.71-6.66)$ & $<0.001$ & $2.61(1.17-5.80)$ & 0.018 \\
\hline Edentulous with $2 \mathrm{CD}$ & $34(29.1)$ & $146(39.2)$ & $3.29(1.76-6.16)$ & $<0.001$ & $2.34(1.11-4.93)$ & 0.025 \\
\hline Edentulous with $1 \mathrm{CD}$ & $12(10.3)$ & $41(11.0)$ & $2.56(1.13-5.78)$ & 0.028 & $2.64(1.01-6.95)$ & 0.049 \\
\hline
\end{tabular}

$C D$ : complete removable denture; Constant model: estimate $=-1.69 ; \mathrm{SE}=0.38 ; \chi^{2}$ wald $=19.47 ; \mathrm{p}<0.001$. 
parameter. These results bring to light quality of life issues regarding total removable prosthetic rehabilitation with respect to nutritional aspects, as denture use is associated with decreased masticatory efficiency ${ }^{12}$. Although dental prostheses can help with aesthetic issues and restore function to a certain degree, a study has shown that impairment of normal oral neurosensory perceptions and masticatory force is irreversible ${ }^{38}$.

The effects of poor oral health status of elderly persons resulting from extensive tooth loss and a poor diet, have been documented in the literature. They range from interference in appetite ${ }^{14}$ and digestive process - by affecting chewing and swallowing ${ }^{12,27}$ - to the selection of foods with a low fiber content, and the preference for a nutritiously poor soft diet ${ }^{12,13,19}$. Elderly with fewer teeth or those who were edentulous reported that they avoid hard-to-chew foods, such as apples and raw vegetables, more often than elderly with more teeth, thus substantially decreasing the general intake of fiber-rich foods ${ }^{14,26}$. In the present study, despite the fact that quality and quantity of the diet was not the focus of investigation, it may be assumed that changes in the dietary pattern of the older persons with an impaired oral situation explain the association found between oral health status and central obesity.

The relationship between oral health and nutritional condition is a complex one. For example, it is difficult to affirm whether tooth loss predicts $\mathrm{CO}$ or vice versa. In line with global food recommendations for the prevention of obesity and other diet-related chronic diseases, a diet rich in fruit, vegetables and grain, and restricted in free sugars and fat, will also benefit many aspects of oral health. As such, a healthy diet can prevent caries ${ }^{39}$, which, along with periodontal problems, is the cause of tooth loss in many cases ${ }^{40}$. Therefore, a reverse causality could be implicated in our findings, since people who have a poor diet tend to be overweight and obese, and in turn, have an unsatisfactory oral health status. Nevertheless, this unlikely is the case in this study, because the extensive tooth loss found is probably the result of cumulative effect of dental diseases that occurred throughout the life of these individuals. As with adults of lower social classes that depend on public dental care, socially disadvantaged Brazilian elderly have been unassisted for long periods of time, and in many instances the only dental care available to them was for pain relief or emergency care, which often involves mutilating approaches such as dental extractions ${ }^{4,24}$.

In Brazil, despite the fact that the current oral health policy has created the Specialized Dental Care Centers and prosthesis laboratories, the common delays in care provision are often discouraging for the population that depends on such care. This is highly concerning because, as our study showed, a high proportion of individuals with $\mathrm{CO}$ have poor oral health and urgently need dental care. Because $\mathrm{CO}$ is a risk factor for a number of general health conditions ${ }^{23}$, the findings of the present study highlight that in order to obtain a better quality of life for this population, it is indispensable that oral health care receive the proper attention, and duly financial support to promote an adequate rehabilitation for these individuals. Health promotion strategies should incorporate the need to retain a natural and functional dentition into old age to avoid diet restriction ${ }^{13}$.

This study has some limitations, especially considering the cross-sectional design; therefore, causality cannot be inferred. In this case, the application of the Poisson regression with a robust adjustment of variance could have been considered to avoid possible overestimation of the odds ratios obtained using logistic regression. The analyses did not account for confounding variables, although the purpose of the study was to explore the prediction of the model.

Also, the prostheses' conditions used by the participants were not evaluated and some might had been inadequate due to long time without clinical maintenance, leading to lack of adaptation and tooth wear; this may have influenced the association of this variable with the dependent variables. Moreover, another possible limitation was the sample selection method, which involved only elderly who were enrolled in the Basic Health Units. Thus, the results should not be generalized to other elderly populations, given the particularly low socioeconomic level of this sample. Further research is needed to confirm these findings in diverse elderly populations. 


\section{Conclusions}

Extensive tooth loss, whether partial or complete, even if rehabilitated by the use of removable prostheses may be considered potential predictors of central obesity in Brazilian independent-living

\section{References}

1. Veras R. Population aging today: demands, challenges and innovations. Rev Saúde Pública. 2009;43(3):548-54. doi:10.1590/S0034-89102009000300020

2. Carvalho JAM, Rodriguez-Wong LL. [The changing age distribution of the Brazilian population in the first half of the 21st century]. Cad Saúde Pública. 2008;24(3):597-605. Portuguese. doi:10.1590/S0102-311X2008000300013

3. Carvalho LaF, Camino ACC, Leite F, Rodrigues cg, Santos GMM, Silva ARA.. Envelhecimento populacional e os desafios para o sistema de saúde brasileiro. São Paulo: Instituto de Estudos de Saúde Suplementar; 2013.

4. Petersen PE, Yamamoto T. Improving the oral health of older people: the approach of the WHO Global Oral Health Programme. Community Dent Oral Epidemiol. 2005;33(2):81-92. doi:10.1111/j.1600-0528.2004.00219.x

5. Santos RD, Gagliardi ACM, Xavier HT, Magnoni $\mathrm{CD}$, Cassani R, Lottenberg AM, et al. Sociedade Brasileira de Cardiologia. I Diretriz sobre o consumo de gorduras e saúde cardiovascular. Arq Bras Cardiol. 2013;100 (1 Suppl3):1-40. doi:10.5935/abc.2013S003

6. Simão AF, Precoma DB, Andrade JP, Correa Filho H, Saraiva JFK, Oliveira GMM et al. I Diretriz Brasileira de Prevenção Cardiovascular. Arq Bras Cardiol. 2013;101(6 Suppl.2):1-63. doi:10.5935/abc.2013S012

7. World Health Organization - WHO. Cardiovascular diseases (CVDs). Geneva: Word Health Organization; 2011 [2013 May 3]. Available from: http://www.who.int/ mediacentre/factsheets/fs317/en/index.html

8. Andrade JP, Mattos LAP, Carvalho AC, Machado CA, Oliveira GMM. National physician qualification program in cardiovascular disease prevention and integral care. Arq Bras Cardiol. 2013;100(3):203-11. doi:10.5935/abc.20130061

9. Johansson I, Tidehag P, Lundberg V, Hallmans G. Dental status, diet and cardiovascular risk factors in middle-aged people in Northern Sweden. Community Dent Oral Epidemiol. 1994;22(6):431-6. doi:10.1111/j.1600-0528.1994.tb00792.x

10. Castro LCV, Franceschini SCC, Priore SE, Peluzio MCG. [Nutrition and cardiovascular diseases: the risk markers in adults]. Rev Nutr. 2004;17(3):369-77. Portuguese. doi:10.1590/S1415-52732004000300010 elderly. Public health policies aimed at preserving natural teeth, as well as providing adequate oral health rehabilitation for the elderly may positively impact oral health, as well as overall health at the population level.

11. Syrjälä AMH, Ylöstalo P, Hartikainen S, Sulkava R, Knuuttila M. Number of teeth and selected cardiovascular risk factors among elderly people. Gerodontology. 2010;27(3):189-92. doi:10.1111/j.1741-2358.2009.00328.x

12. Sheiham A, Steele JG, Marcenes W, Finch S, Walls AWG. The relationship between oral health status and Body Mass Index among older people: a national survey of older people in Great Britain. Br Dent J. 2002;192(12):703-6. doi:10.1038/sj.bdj.4801461

13. Marcenes W, Steele JG, Sheiham A, Walls AWG. The relationship between dental status, food selection, nutrient intake, nutritional status, and body mass index in older people. Cad Saúde Pública. 2003;19(3):809-16. doi:10.1590/S0102-311X2003000300013

14. Savoca MR, Arcury TA, Leng X, Chen H, Bell RA, Anderson AM, et al. Severe tooth loss in older adults as a key indicator of compromised dietary quality. Public Health Nutr. 2010;13(4):466-74. doi:10.1017/S1368980009991236

15. Hilgert JB, Hugo FN, Souza MLR, Bozzetti MC. Oral status and its association with obesity in Southern Brazilian older people. Gerodontology 2009;26(1):46-52. doi:10.1111/j.1741-2358.2008.00226.x

16. De Marchi RJ, Hugo FN, Hilgert JB, Padilha DMP. Number of teeth and its association with central obesity in older Southern Brazilians. Community Dent Health. 2012;29(1):85-9. doi:10.1922/CDH_2676Marchi05

17. Östberg AL, Bengtsson C, Lissner L, Hakeberg M. Oral health and obesity indicators. BMC Oral Health. 2012;12(1):50. doi:10.1186/1472-6831-12-50

18. Tôrres LH, Silva DD, Neri AL, Hilgert JB, Hugo FN, Sousa ML. Association between underweight and overweight/obesity with oral health among independently living Brazilian elderly. Nutrition. 2013;29(1):152-7. doi:0.1016/j.nut.2012.05.011

19. De Marchi RJ, Hugo FN, Hilgert JB, Padilha DMP. Association between oral health status and nutritional status in south Brazilian independent-living older people. Nutrition. 2008;24(6)546-53. doi:10.1016/j.nut.2008.01.054

20. De Marchi RJ, Hugo FN, Hilgert JB, Padilha DMP. Association between number of teeth, edentulism and use of dentures with percentage body fat in south Brazilian community-dwelling older people. Gerodontology. 2012;29(2):e69-76. doi:10.1111/j.1741-2358.2010.00411.x 
21. Xavier HT, Izar MC, Faria Neto JR, Assad MH, Rocha VZ, Sposito AC et al. [V Brazilian guidelines on dyslipidemias and prevention of atherosclerosis]. Arq Bras Cardiol. 2013;10 (4 suppl.1):1-22. doi:10.5935/abc.2013S010

22. Balkau B, Deanfield JE, Després JP, Bassand JP, Fox KA, Smith SC Jr et al. International Day for the Evaluation of Abdominal Obesity (IDEA): a study of waist circumference, cardiovascular disease, and diabetes mellitus in 168,000 primary care patients in 63 countries. Circulation. 2007;116(17):1942-51. doi:10.1161/CIRCULATIONAHA.106.676379

23. Rosengren A, Hawken S, Ounpuu S, Sliwa K, Zubaid M, Almahmeed WA et al. Association of psychosocial risk factors with risk of acute myocardial infarction in 11119 cases and 13648 controls from 52 countries (the INTERHEART study): case-control study. Lancet. 2004;364(9438):953-62. doi:10.1016/S0140-6736(04)17019-0

24. Peres MA, Barbato PR, Reis SCGB, Freitas CHSM, Antunes JL. Perdas dentárias no Brasil: análise da Pesquisa Nacional de Saúde Bucal 2010. Rev Saúde Pública. 2013;47(Suppl 3):78-89. doi:10.1590/S0034-8910.2013047004226

25. Ulinski KGB, Nascimento MA, Lima AMC, Benetti AR, Poli-Frederico RC, Fernandes KBP et al. Factors related to oral health-related quality of life of independent Brazilian elderly. Int J Dent. 2013;2013:705047. doi:10.1155/2013/705047

26. Hung HC, Colditz G, Joshipura KJ. The association between tooth loss and the self-reported intake of selected CVD-related nutrients and foods among US women. Community Dent Oral Epidemiol. 2005;33(3):167-73. doi:10.1111/j.1600-0528.2005.00200.x

27. Rodrigues HLJr, Scelza MF, Boaventura GT, Custódio SM, Moreira EA, Oliveira DL. Relation between oral health and nutritional condition in the elderly. J Appl Oral Sci. 2012;20(1):38-44. doi:10.1590/S1678-77572012000100008

28. Instituto Brasileiro de Geografia e Estatística - IBGE. Cidades@. Available from: http://www.ibge.gov.br/cidadesat

29. Barbeta PA. Estatística aplicada às ciências sociais. 7a ed. Florianópolis: Ed.UFSC; 2007. Chapter 7, Fórmula para o cálculo do tamanho mínimo da amostra; p. 315.

30. Spirduso WW. Dimensões físicas do envelhecimento. Barueri: Manole; 2005.
31. Associação Brasileira de Empresas de Pesquisa - ABEP. Critério de classificação econômica Brasil (CCEB). São Paulo: ABEP; 2008 [cited 2012 Jun 20]. Available at: http:// www.abep.org

32. World Health Organization - WHO. Oral health surveys: basic methods. 4th ed. Geneva: World Health Organization;1997.

33. Mion JRD, Kohlmann JRO, Machado CA, Amodeo C, Gomes MAG, Praxedes JN et al. V Diretrizes brasileiras de hipertensão arterial. Rev Bras Hipertens. 2006;13(4):256-312.

34. World Health Organization - WHO. Guidelines for the conduct of the tobacco smoking surveys of the general population: report of a meeting. Geneva: World Health Organization; 1992.

35. Klein S, Allison DB, Heymsfield SB, Kelley DE, Leibel RL, Nonas C et al. Waist circumference and cardiometabolic risk: a consensus statement from shaping America's health: association for weight management and obesity prevention. Am J Clin Nutr. 2007;85(5):1197-202.

36. World Health Organization - WHO. Obesity: preventing and managing the global epidemic: Report of a WHO Consultation (TRS894). Geneva: World Health Organization; 2000.

37. Hosmer DW, Lemeshow S, Sturdivant RX. Applied logistic regression, Wiley series in probability and statistics. 3rd ed. Hoboken: John Wiley \& Sons; 2013.

38. Yoshihara A, Watanabe R, Hanada N, Miyazaki H. A longitudinal study of the relationship between diet intake and dental caries and periodontal disease in elderly Japanese subjects. Gerodontology. 2009;26(2):130-6. doi:10.1111/j.1741-2358.2008.00244.x

39. Moynihan PJ. The role of diet and nutrition in the etiology and prevention of oral diseases. Bull World Health Organ. 2005;83(9):694-9. doi:10.1590/S0042-96862005000900015

40. Muñoz-Torres FJ, Jiménez MC, Rivas-Tumanyan S, Joshipura KJ. Associations between measures of central adiposity and periodontitis among older adults. Community Dent Oral Epidemiol 2014;42(2):170-7. doi:10.1111/cdoe.12069 